\title{
EKSTRAKSI ION MERKURI MENGGUNAKAN TEKNIK EMULSI MEMBRAN CAIR DENGAN VARIASI KONSENTRASI BENZOIL ASETON DALAM FASA MEMBRAN DAN VARIASI PH FASA EKSTERNAL
}

\author{
Mercury Ion Extraction Using the Liquid Membrane Emulsion Technique with \\ Variation of Benzoil Aseton Concentration in Membrane Phase and Variation of Ph of \\ External Phase
}

*Sulniawati, Baharuddin Hamzah dan Paulus H. Abram

Pendidikan Kimia/FKIP - Universitas Tadulako, Palu - Indonesia 94118

Received 15 September 2017, Revised 16 October 2017, Accepted 17 November 2017

\begin{abstract}
Mercury ion extraction using the liquid membrane emulsion technique with variation of benzoil aseton concentration in membrane phase and variation of $p H$ of external phase has been done. The sample containing $\mathrm{Hg}^{2+}$ ions with a concentration of $20 \mathrm{mg} / \mathrm{L}$. Variation of benzoil aseton were concentration of $0.01 \mathrm{M}, 0.015$ $M, 0.02 M$ and $0.025 M$, whereas variation of external phase $p H$ used were 1,5; 2; 2,5; 3 and 3,5. The measurement of extraction was conducted by using UV-Vis spectrophotometer. The results showed that the largest percent extraction on the extraction of mercury ions in solution by using liquid membrane emulsion was at a concentration of benzoil aseton $0.02 \mathrm{M}$ with the percentage of extraction $79.33 \%$ and the $\mathrm{pH}$ external phase 2 with the percentage of extraction $85.30 \%$.
\end{abstract}

Keywords: Mercury ion, liquid membrane emulsion, benzoil aseton concentration, $p H$ of external phase

\section{Pendahuluan}

Pesatnya perkembangan kegiatan pertambangan mineral seperti emas, tembaga dan nikel baik secara modern atau tradisional, akan memberikan banyak pula dampak merugikan bagi lingkungan kehidupan manusia. Bahaya yang sering ditimbulkan dari kegiatan pertambangan ini berasal dari penggunaan bahan-bahan kimia pada proses amalgamasi menghasilkan tailing (sisa pengolahan) yang mengandung sejumlah logam beracun seperti $\mathrm{As}, \mathrm{Pb}, \mathrm{Hg}$, dan $\mathrm{Cd}$ yang dapat mencemari dan merusak lingkungan (Zulkifli, 2006).

Merkuri merupakan salah satu logam yang berbahaya, ketika memasuki sistem akuatik, limbah yang mengandung merkuri diserap oleh organisme di dalamnya, kemudian dalam tubuh organisme melalaui proses metilasi akan berkembang menjadi metil-merkuri yang bersifat racun (Zulkifli, 2006). Di alam raksa terdapat sebagai raksa organik yaitu raksa yang bersifat molekul dan terikat dengan atom karbon, serta raksa anorganik yaitu merkuri yang terdiri dari raksa unsur dan garam merkurous dan merkuri yang dapat terurai (Alfian, 2006).

Merkuri memang memiliki bahaya yang cukup besar bagi lingkungan dan kesehatan, namun demikian raksa juga memiliki kegunaan yang beragam yaitu dalam bidang pertanian raksa digunakan sebagai bahan pembuatan anti fungi, raksa juga digunakan pada peralatan fisika seperti

*Correspondence

Sulniawati

Program Studi Pendidikan Kimia, Fakultas Keguruan dan Ilmu

Pendidikan, Universitas Tadulako

e-mail:sulniawati01@gmail.com

Published by Universitas Tadulako 2017 barometer dan thermometer. Merkuri banyak digunakan dalam industri penambangan emas, dimana merkuri digunakan sebagai bahan untuk mengikat dan pemisah biji emas dari pasir, lumpur dan air (Subanri, 2008). Untuk menangani masalah yang ditimbulkan dari pengguanaan merkuri khususnya dalam bidang pertambangan ini, maka telah dikembangkan teknik pemisahan logam berat yang dinilai lebih efisien dan efektif yaitu pemisahan dengan teknik membran cair. Salah satu jenis teknik ini adalah teknik membran cair emulsi (emulsion liquid membrane, ELM) yang disebut juga membran cair bersurfaktan (Djunaidi \& Haris, 2003). Ekstraksi ion logam dengan metode membran cair membutuhkan zat pembawa. Zat pembawa (ekstraktan) yang sering digunakan pada ekstraksi logam dengan teknik emulsi membran cair antara lain D2EHPA (Djunaidi \& Haris, 2003) dan ditizon (Tuljannah, 2013). Oleh karena itu dibutuhkan suatu ekstraktan yang penggunaannya lebih sedikit, lebih efisien dan dapat memberikan persen ekstraksi yang lebih tinggi (Hamzah, dkk., 2013)

Teknik emulsi membran cair merupakan teknik yang potensial dan efektif dalam proses pemisahan logam (Mok, dkk., 1997). Kelebihan utama teknik emulsi membran cair adalah zat yang diekstraksi dapat dipekatkan hingga sepuluh kali lipat karena pada umumnya perbandingan volume fasa eksternal dan fasa internal adalah $10: 1$ dan laju transport yang jauh lebih cepat (Izatt, dkk., 1986).

Emulsi membran cair dikenal sebagai sistem emulsi ganda.Emulsi terdiri dari 2 tipe yaitu pertama emulsi air dalam minyak (W/O) emulsi minyak dalam air $(\mathrm{O} / \mathrm{W})$ dimana emulsi air dalam minyak (W/O) (Alam, 2014). Emulsi membran cair dibuat dengan membentuk emulsi dari dua 
fasa cair yang tidak saling campur dan kemudian emulsi yang terbentuk didispersikan ke fasa eksternal (Bartsch \& Way, 1996).

Dalam pembuatan emulsi diperlukan emulgator yang dapat menurunkan tegangan permukaan antara minyak dan air sehingga diperoleh emulsi yang stabil.Untuk membentuk emulsi yang stabil, emulgator memerlukan harga HLB yang sesuai dengan HLB butuh dari minyak yang digunakan (kerosen). HLB (Hydrophilic-Lipophilic Balance) adalah harga yang harus dimiliki oleh sebuah emulgator sehingga pertemuan antar fase lipofil dengan air dapat mengahasilkan emulsi dengan tingkat dispersitas dan stabilitas yang maksimal. Nilai HLB butuh yang dimiliki kerosen untuk emulsi W/O sebesar 6,0 dan untuk emulsi O/W sebesar 14,0 (Kloet \& Schra, 2002). Menurut penelitian lain untuk emulsi tipe O/W HLB butuh kerosen sebesar 12,0 (Abismail, dkk., 2000).

Banyak variabel yang akan menentukan persen ekstraksi yang diperoleh dalam pemisahan ion merkuri dengan teknik membrane cair, diantaranya yaitu perbandingan volume fasa membran dan fasa internal, pengaruh lama waktu ekstraksi, pengaruh konsentrasi surfaktan, konsentrasi asam klorida, pengaruh perbandingan fasa emulsi dan fasa eksternal.

Tulisan ini dimaksudkan untuk memberikan informasi tentang konsentrasi benzoil aseton dalam fasa membran dan $\mathrm{pH}$ fasa eksternal yang menghasilkan persen ekstraksi ion merkuri terbesar menggunakan teknik emulsi membran cair.

\section{Metode}

Peralatan utama yang digunakan dalam penelitian ini adalah seperangkat peralatan gelas, seperangkat alat ekstraksi, $\mathrm{pH}$ meter Lamotte, pipet volume, karet penghisap, neraca digital $A N D G R$ 200, pipet tetes, corong pisah, statif dan klem, spatula, batang pengaduk, cimarec stirring and hot plate, magnetic strirrer, kuvet dan UV-VisPerkin Elmer Lambda 25.

Bahan-bahan yang digunakan dalam penelitian ini meliputi: kristal $\mathrm{HgCl}_{2}$ (E. Merk), benzoil aseton (Merck Schuchardt OHG), span 20 (Merck Schuchardt OHGI) dan span 80 (Merck Schuchardt $O H G)$, kerosen, ditizon dalam $\mathrm{CCl}_{4}$, aquades, serta asam klorida (Merck).

Variasi konsentrasi benzoil aseton dalam fasa membran terhadap persen ekstraksi ion merkuri

$30 \mathrm{~mL}$ emulsi ditambahkan ke dalam $150 \mathrm{~mL}$ larutan $\mathrm{HgCl}_{2} 20 \mathrm{ppm}$ pada $\mathrm{pH}$ 3. Emulsi dibuat melalui pencampuran fasa membran (yang mengandung $0,01 \mathrm{M} ; 0,015 \mathrm{M} ; 0,02 \mathrm{M}$ dan 0,025 $\mathrm{M}$ benzoil aseton dan $4 \%$ surfaktan campuran) dan fasa internal dengan perbandingan volume 2:2dengan kecepatan emulsifikasi menggunakan skala 10 selama 10 menit. Proses ekstraksi dilakukan dengan kecepatan pengadukan pada skala 1,5 selama 10 menit. Setelah ekstraksi, fasa eksternal dipisahkan dari emulsi dan diukur konsentrasi ion merkuri dengan spektrofotometer UV-Vis. Konsentrasi benzoil aseton yang memberikan persen ekstraksi ion merkuri terbanayak adalah konsentrasi benzoil aseton optimum.

\section{Variasi $p H$ fasa eksternal terhadap persen} ekstraksi ion merkuri

Langkah kerja variasi pertama diulangi dengan menerapakan konsentrasi benzoil aseton optimum, hanya saja pada langkah ini dilakukan variasi terhadap $\mathrm{pH}$ fasa esternal, adapun variasi $\mathrm{pH}$ yang digunakan yaitu 1,$5 ; 2 ; 2,5 ; 3$ dan $3,5 . \mathrm{pH}$ fasa eksternal yang memberikan persen ekstraksi terbanyak adalah $\mathrm{pH}$ fasa eksternal optimum.

\section{Analisis kandungan merkuri yang tersisa}

$5 \mathrm{~mL}$ larutan ditizone $0,001 \%$ dalam $\mathrm{CCl}_{4}$ ditambahkan ke dalam sampel yang tersisa pada fasa eksternal, kemudian dikocok selama 1 menit. Bila warna yang dihasilkan kurang stabil, tambahkan larutan ditizone hingga diperoleh warna yang stabil. Larutan standar yang digunakan terdiri dari beberapa konsentrasi yaitu $0,05 \mathrm{ppm}$; $0,15 \mathrm{ppm} ; 0,25 \mathrm{ppm} ; 0,35 \mathrm{ppm}$ dan 0,5 ppm. Selanjutnya larutan standar dikomplekskan dengan larutan ditizone dalam $\mathrm{CCl}_{4}$. Kemudian sampel dianalisis dengan menggunakan instrumen spektrofotometer UV-Vis pada panjang gelombang $490 \mathrm{~nm}$.

\section{Hasil Dan Pembahasan}

\section{Pengukuran absorbansi larutan standar}

Analisis kuantitatif yang dilakukan pada penentuan ion merkuriadalahdengan metode spektrofotometer UV-Vis. Pada penentuan logam merkuri dengan metode spektrofotometer UV-Vis digunakan penggompleks ditizon dalam $\mathrm{CCl}_{4}$, sehingga terbentuk senyawa kompleks $\mathrm{Hg}(\mathrm{HDz})$ atau merkuri ditizonat. Ion logam merkuri $\left(\mathrm{Hg}^{2+}\right)$ dan ditizone dapat bereaksi membentuk kompleks merkuri ditizonat yang berwarna orange, dan dapat dianalisis dengan spektrofotometerUV-Vis. Reaksi antara ion $\mathrm{Hg}^{2+}$ dengan pereaksi ditizon( $\mathrm{HDz}$, ditunjukkan dalam persamaan dibawah ini

$\mathrm{Hg}+2 \mathrm{H}_{2} \mathrm{Dz}(\mathrm{o}) \rightleftarrows \mathrm{Hg}(\mathrm{HDz})_{2}+2 \mathrm{H}$

Adapun struktur senyawa kompleks merkuri ditizonat ditunjukkan dalam Gambar 1 .

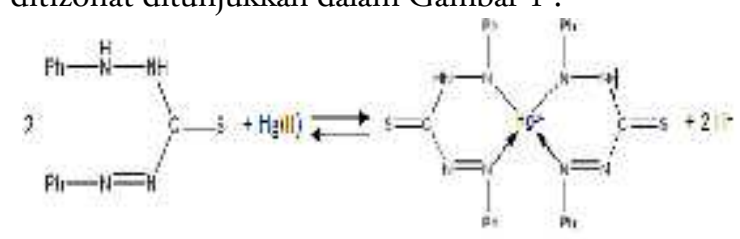

Gambar 1. Struktur senyawa kompleks merkuriditizonat (Cahyani, 2014)

Pertama-tama dilakukan pengukuran absorbansi larutan standar, konsentrasi larutan standar yang digunakan yaitu konsentrasi $0,1 \mathrm{ppm}$, 0,2 ppm, 0,3 ppm, 0,4 ppm dan 0,5 ppm. Panjang gelombang maksimum yang digunakan dalam 
pengukuran absorbansi larutan standar maupun larutans ampel adalah pada panjang gelombang $490 \mathrm{~nm}$. Penyerapan energy foton pada panjang gelombang $490 \mathrm{~nm}$ melibatkan perpindahan electron dari donor ke akseptor, dan dalam ditizon atomN pada ligan ditizon merupakan donor pasangan elektron (basa Lewis) sedangkan ion logam $\mathrm{Hg}(\mathrm{II})$ merupakan akseptor pasangan electron (asam Lewis) (Cahyani, 2014).

Hubungan antara konsentrasi dan absorbansi larutan standar yang diperoleh, menjelaskan bahwa adanya linearitas antara konsentrasi dan absorbansi. Persamaan garis linier yang merupakan hubungan antara absorbansi (y) dan konsentrasi (x) larutan standar yaitu $y=2,245 x+0,026$ dengan nilai koefisien korelasi yang diperoleh yaitu 0,884 , nilai koefisien korelasi yang mendekati 1 menunjukkan adanya hubungan yang linear antara absorbansi yang terukur dengan konsentrasi.

\section{Variasi konsentrasi benzoil aseton terhadap persen ekstraksi ion merkuri}

Sampel yang dihasilkan dengan memvariasikan konsentrasi benzoil aseton kemudian diencerkan dengan menggunakan aquades. Pengenceran dilakukan sampai $20 \mathrm{kali}$ volume sampel. Hasil pengenceran kemudian dikomplekskan dengan penambahan ditizone dalam $\mathrm{CCl}_{4}$ selanjutnya mengukur absorbansinya menggunakan spektrofotometri UV-Vis pada panjang gelombang $490 \mathrm{~nm}$. Adapun hasil yang diperoleh pada sampel dengan variasi konsentrasi benzoil aseton ini dapat dilihat pada Gambar 2.

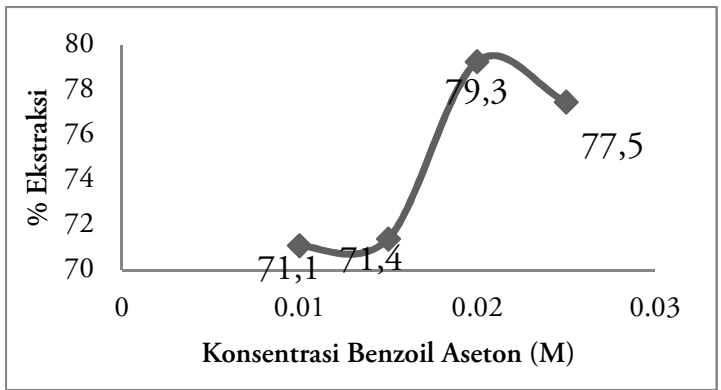

Gambar 2. Grafik variasi konsentrasi benzoilaseton terhadap persen ekstraksi ion merkuri

Berdasarkan Gambar 2 terlihat bahwa variasi konsentrasi benzoilaseton yang memberikan persen ekstraksi terbesar adalah pada konsentrasi 0,02 M atau 0,0792 gram.

Semakin besar jumlah benzoil aseton (ekstrakan) maka semakin tinggi pula kecepatan ekstraksi. Namun besarnya konsentrasi yang dperlukan dalam mengekstraksi suatu logam (merkuri) mempunyai harga optimum tertentu. Proses pengikatan logam merupakan proses keseimbangan pembentukan kompleks logam dengan senyawa pengkelat (benzoil aseton) (Harunsyah, 2011). Sehingga dapat disimpulkan bahwa proses pengkelatan sangat dipengaruhi oleh konsentrasi senyawa yang ada, dimana apabila konsentrasi berada di bawah atau di atas kondisi optimum akan menyebabkan terjadi reaksi yang berbeda. Pada konsentrasi benzoil aseton di bawah kondisi optimum yaitu 0,01 $\mathrm{M}$ dan 0,015 M menyebabkan benzoil aseton tidak cukup mampu untuk mengkomplekskan semua ion merkuri yang ada dalam larutan, sehingga anion-anion yang ada dalam larutan ikut serta berperan dalam pembentukan kompleks logam.

Penggunaan konsentrasi benzoil aseton di atas harga optimum yaitu 0,025 M tidak akan banyak mempengaruhi hasil ekstraksi, karena benzoil aseton sebagai zat pembawa dalam hal ini bersifat mobil di dalam membran. Setelah senyawa zat pembawa melepas ion logam pada fasa internal, zat pembawa ini akan segera berdifusi balik ke fasa eksternal untuk mengkomplekskan ion logam kembali. Pemakaian zat pembawa yang terlalu besar akan menyebabkan terjadinya interaksi gugus polar zat pembawa dengan air dalam fasa eksternal sehingga mendorong proses osmosa (Prayitno, dkk., 1996).

\section{Variasi pH fasa eksternal terhadap persen ekstraksi ion merkuri}

Konsentrasi benzoil aseton yang memberikan persen ekstraksi terbesar yaitu pada konsentrasi 0,02 M dengan persen ekstraksi $80,79 \%$. Kondisi optimum ini kemudian akan digunakan dalam variabel berikutnya yaitu variasi $\mathrm{pH}$ fasa eksternal. Adapun variasi $\mathrm{pH}$ fasa eksternal yang digunakan adalah 1,$5 ; 2 ; 2,5 ; 3$ dan 3,5. Pada variabel kedua sampel yang diperoleh dari hasil ekstraksi diencerkan dengan menggunakan aquadaes hingga volumenya menjadi 30 kali dari volume sampel. Absorbansi yang diperoleh dari hasil analisis ini yang kemudianakan digunakan dalam penentuan konsentrasi sampel dan persen ekstraksi. Berdasarkan data hasil analisis maka diperoleh hasil persen ekstraksi ion merkuri seperti yang ditunjukkan pada Gambar 3.

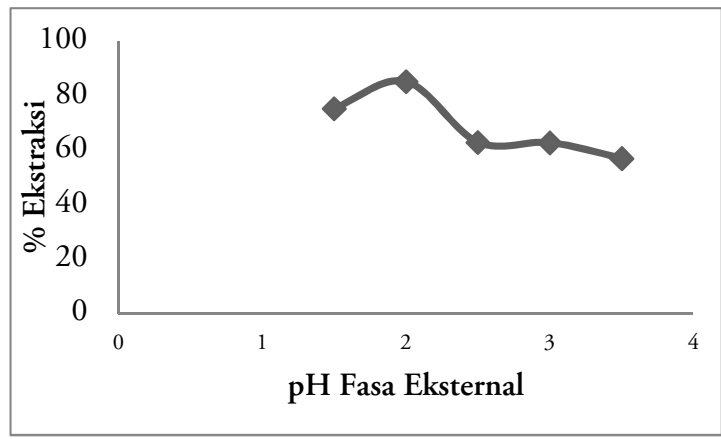

Gambar 3. Grafik variasi $\mathrm{pH}$ fasa eksternal terhadap persen ekstraksi ion merkuri

Berdasarkan pada Gambar 3 terlihat bahwa variasi $\mathrm{pH}$ fasa eksternal yang memberikan persen ekstraksi terbesar adalah pada pH 2. Grafik di atas menunjukkan bahwa ion merkuri relatif dapat diekstraksi dengan baik pada fasa eksternal pH 2 . Peran anion hydrogen sangat penting pada transpor (ekstraksi) yang dibantu senyawa pembawa (benzoil 
aseton). Kompleks logam $\mathrm{Hg}\left(\mathrm{C}_{10} \mathrm{H}_{10} \mathrm{O}_{2}\right)_{2}$ bisa mencapai fasa internal dibantu oleh ion hidrogen tersebut. Sehingga bias dikatakan bahwa gradien $\mathrm{pH}$ antara fasa eksternal dan fasa internal juga termasuk komponen gaya dorong transport. Jika $\mathrm{pH}$ fasa penerima dibuat pada $\mathrm{pH} 1$, maka gradient konsentrasi ion hydrogen antara fasa eksternal dan fasa internal belum berarti, sehingga transpor atau ekstraksi pada $\mathrm{pH}$ ini belum optimal. Sedangkan peningkatan $\mathrm{pH}$ di atas 2 yaitu 2,5; 3 dan 3,5 persen ekstraksi ion merkuri yang dihasilkan relatif menurun (Sulaiman, dkk., 2006) dan menyebabkan terjadinya endapan cukup besar mengingat $K_{s p}$ hidroksi logam berat sangat kecil (Djunaidi \& Haris, 2003). Hasil dari penelitian ini juga sesuai dengan hasil yang diperoleh Cahyani (2014) yang menyatakan bahwa spesi $\mathrm{Hg}^{2+}$ terbentuk maksimal pada $\mathrm{pH} 2$.

\section{Kesimpulan}

Konsentrasi benzoil aseton yang memberikan persen ekstraksi terbesar pada proses ekstraksi ion merkuri dengan teknik emulsi membran cair yaitu pada konsentrasi $0,02 \mathrm{M}$ dengan persen ekstraksi (\%E) sebesar 79,33\% serta $\mathrm{pH}$ fasa eksternal yang memberikan persen ekstraksi terbesar pada proses ekstraksi ion merkuri dengan teknik emulsi membran cair yaitu pada $\mathrm{pH} 2$ dengan persen ekstraksi sebesar 85,301\%.

\section{Ucapan Terima Kasih}

Penulis menyampaikan ucapan terima kasih kepada Tasrik, Husnia dan Nurbaya selaku laboran di Laboratorium Kimia FKIP Universitas Tadulako.

\section{Referensi}

Abismail, B., Canselier, J., Wilhelm, A., Delmas, H. \& Gourdon. (2000). Emulsification process: On-line study by multiple light scattering measurements. Ultrasonics Sonochemistry, 7(1), 187-192.

Alam, S. (2014). Penentuan kondisi optimum ekstraksi ion timbal(II) smenggunakan teknik emulsi membran cair. Jurnal Akademika Kimia, 3(2), 329-335

Alfian, Z. (2006). Merkuri: Antara manfaat dan efek penggunaannya bagi kesehatan manusia dan lingkungan.Pidato Pengukuhan Jabatan Guru Besar Tetap dalam Bidang Ilmu Kimia Analitik, Medan.

Bartsch, R. A. \& Way, J. D. (1996). Chemical separations with liquid membranes. American Chemical Society, 6(12), 1-2.
Cahyani, A. D. (2014). Pengujian metode spektrofotometri UV-Visible untuk penentuan Hg(II) dalam limbah cair laboratorium kimia analitik FMIPA UGM dengan pereaksi ditizon. Skripsi Sarjana pada FMIPA Universitas Gadjah Mada, Yogyakarta

Djunaidi, C. \& Haris, A. (2003). Pemisahan logam berat menggunakan membran cair berpendukung dengan variabel konsentrasi ion logam dan $\mathrm{pH}$ fasa umpan. Jurnal Kimia Sains dan Aplikasi, 6(2), 1-4.

Hamzah, B., Pulukadang, S. H.\& Hardani, R. (2013). Sintesis ekstraktan turunan pirazolon dan uji kestabilan emulsi untuk ekstraksi ion raksa(II) menggunakan teknik emulsi membran cair. Prosiding Seminar Nasional Sains dan Matematika II pada Jurusan Pendidikan MIPA FKIP Universitas Tadulako.

Hamzah, B., Jalaluddin, N., Wahab, A. W. \& Upe, A. (2011). Pengaruh ion kadmium(II) dan nikel(II) pada ekstraksi ion tembaga(II) dengan ekstraktan 4-Benzoil-1-Fenil-3-Metil2-Pirazolin-5-On menggunakan emulsi membran cair. Natur Indonesia, 13(3), 269275.

Harunsyah. (2011). Peningkatan mutu minyak nilam rakyat melalui proses pemurnian,Jurnal Teknologi Politeknik Negeri Lhokseumawe, 11(1), 3-4.

Izatt, R. M., Lindh, Bruening, R. L., Bradshaw, J. S., Lamb, J. D. \& Christensen J. J. (1986). Design of cation selectivity into liquid membrane systems using macrocyclic carriers. Pure \& Appl. Chem., 58(11), 1453-1460.

Kloet, J. V. \& Schra, L. I. (2002). The effect of shear and oil/water ratio on the required hydrophile-lipophile balance for emulsification. Journal of Surfactants and Detergents, 5(1), 19-24.

Mok, Y. S., Lee, W. K. \& Lee, Y. K. (1997). Modeling of liquid emulsion membranes facilitated by two carriers.Jurnal of Chemical Engineering Science, 66(1), 11-20.

Prayitno, Basuki, K. T., Susanto, Hardjoto \& Raharjo. (1996). Ekstraksi uranium sebagai kompleks uranil nitrat dalam asam nitrat dengan teknik emulsi membran cair.Prosiding Presentasi Ilmiah Daur Bahan Bakar Nuklir II $P E B N$, Pusat Penelitian Nuklir Yogyakarta. 
Subanri. (2008). Kajian beban pencemaran merkuri $(\mathrm{Hg})$ terhadap air sungai menyuke dan gangguan kesehatan pada penambang sebagai akibat penambangan emas tanpa Izin (PETI) di Kecamatan Menyuke Kabupaten Landak Kalimanan Barat. Proposal Tesis. Semarang: Program Pasca Sarjana Megister Kesehatan Lingkungan Universitas Diponegoro,.

Sulaiman, A., Buchari \& Mardiman, U. (2006). Pemisahan serium dari mineral monasit dengan teknik SLM bertingkat. Jurnal Kimia Indonesia, 1(1), 1-6.
Tuljannah, N. (2013). Ekstraksi ion tembaga(II) dengan metode emulsi membran cair menggunakan ditizon sebagai pembawa kation.Jurnal Akademika Kimia, 2(2), 76-81

Zulkifli, D. (2006). Tinjauan terhadap tailing mengandung unsur pencemar arsen (As), merkuri $(\mathrm{Hg})$, timbal $(\mathrm{Pb})$, dan kadmium $(\mathrm{Cd})$ dari sisa pengolahan bijih logam. Geologi Indonesia, 1(1), 31-36. 